\title{
Screening recurrence and lymph node metastases in head and neck cancer: the role of computer tomography in follow-up
}

\author{
Valentina Rivelli, Heinz T Luebbers, Franz E Weber, Claudia Cordella, Klaus W Grätz and Astrid L Kruse*
}

\begin{abstract}
Introduction: Follow-up of patients with oral cancer is being questioned with regard to financial costs and effectiveness. Therefore, the aim of the present study was to evaluate whether local recurrence and cervical lymph node metastases were first discovered clinically or by routine computer tomography.

Materials and methods: The records of all 317 patients that were treated for an oral cancer between 1998 and 2008 were systematically reviewed. Criteria for inclusion were tumor histology with a squamous cell carcinoma of the head and neck, and regular follow-up examinations with a minimum follow-up time of 12 months, including clinical and radiological (CT) controls. All patients had the first CT after 6 months, followed by yearly CT controls.

Results: Out of 315 patients with an oral squamous cell carcinoma, 294 were evaluated. Those experiencing neither recurrence of the tumor nor lymph node metastases constituted $62 \%$. Local recurrence was seen in 36 (12\%), lymph node metastases in $32(11 \%)$, and both in 16 (6\%). Of the 32 patients with lymph node metastases, 25 were recognized first clinically, and 7 were detected by routine CT scans; concerning local recurrence, 32 appeared clinically, and 4 were detected by routine CT scans.
\end{abstract}

Conclusion: Routine CT for follow-up is still indicated for detecting lymph node metastases as well as local recurrence.

\section{Introduction}

The 5-year disease-specific survival rate for patients with primary oral cancer ranges from $53 \%$ [1] to $74 \%$ [2]. Most of the locoregional recurrences and lymph node metastases in head and neck cancer occur within the first two years $[3,4]$. The status of the lymph nodes appears to be one of the most important prognostic factors for patients with squamous cell carcinoma (SCC) of the head and neck, and recurrent disease seems to be associated with decreased survival [5]. Examination of the neck is based mainly on palpation.

Follow-up, including CT scans, of patients with oral cancer is being questioned with regard to financial costs and effectiveness. Most of the studies dealing with detection of cervical lymph node metastases are preoperative assessments. In surgically treated or radiated

\footnotetext{
* Correspondence: astridkruse@gmx.ch
Department of Craniomaxillofacial and Oral Surgery, University Hospital

* Correspondence: astridkruse@gmx.ch
Department of Craniomaxillofacial and Oral Surgery, University Hospital
} Zurich, Zurich, Switzerland

@ 2011 Rivelli et al; licensee BioMed Central Ltd. This is an Open Access article distributed under the terms of the Creative Commons Attribution License (http://creativecommons.org/licenses/by/2.0), which permits unrestricted use, distribution, and reproduction in any medium, provided the original work is properly cited. necks, the assessment seems to be more difficult due to scar tissue. Therefore, the aim of the present study was to evaluate whether local recurrence and cervical lymph node metastases were first discovered clinically or by routine computer tomography.

\section{Materials and methods}

The records of all 317 patients treated for oral cancer between 1998 and 2008 at the Department of Craniomaxillofacial and Oral Surgery, University Hospital Zurich, were systematically reviewed. Criteria for inclusion were tumor histology with an SCC of the head and neck, and regular follow-up examinations, with a minimum follow-up time of 12 months, including clinical and radiological (CT) controls. Criteria for exclusion were inadequate information, tumors in other regions of the head and neck (e.g., salivary glands, skin), and patients with previous oral carcinoma. All patients had the first CT after 6 months, followed by yearly CT controls. Clinical controls were performed once per month 
Table 1 Follow-up schema

\begin{tabular}{lll}
\hline TIME & CLINICAL CONTROL & RADIOLOGICAL CONTROL \\
\hline Year 1 & monthly control & after 6 and 12 months \\
\hline Year 2 & every 2 months control & once a year \\
\hline Year 3 & every 3 months control & once a year \\
\hline Year 4 & every 6 months control & once a year \\
\hline From year 5 & once a year control & only in suspicious cases \\
\hline
\end{tabular}

in the first year; in the second year, every 2 months; in the third year, every 3 months; in the fourth year, every 6 months; and once per year after the fifth year (Table 1 ). Due to inadequate information, only 294 patients were included. Data of recurrence, lymph node metastases, and second head and neck cancer were analyzed.

\section{Results}

Out of 294 patients with an oral squamous cell carcinoma, the male-female ratio was 172:122 with a median age of 62.25 years; those experiencing no tumor recurrence or lymph node metastases constituted $62 \%$. Local recurrence was seen in $36(12 \%)$, lymph node metastases in $32(11 \%)$, and both in $16(6 \%)$ (Figure 1).

Out of 32 patients with lymph node metastases, 25 were first recognized clinically, and 7 were detected by routine CT scans; concerning local recurrence, 32 appeared clinically, and 4 were detected by routine CT scans (Figure 2).

Local recurrences (Figure 3) appear later than lymph node metastases (Figure 4). The combination of both (Figure 5) had the longest time to event. The exact data is given in Table 2.

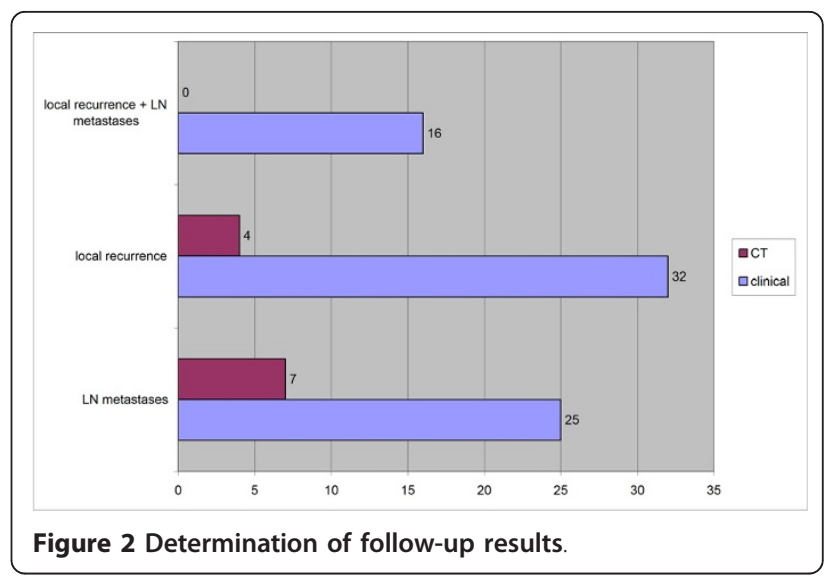

\section{Discussion}

Palpation alone for assessment of cervical lymph node metastases seems to be unreliable [6]. For staging, ultrasonography, computed tomography, and magnetic resonance imaging (MRI) are generally considered superior to palpation [7]. Concerning the comparison between palpation, CT, and low field MRI, Atula et al. were able to show, in 86 patients without palpable normal necks, that CT (23 positive) was superior to low field MRI (10 positive) and ultrasonography (12 positive) [6]. Yousem et al. arrived at similar results by studying central nodal necrosis and extracapsular spread, experiencing a more accurate detection by $\mathrm{CT}$ in comparison to unenhanced or enhanced MRI [8]. In one of the largest meta-analyses, de Bondt et al. showed that ultrasonographyguided fine needle aspiration cytology had the highest diagnostic odds ratio $(\mathrm{DOR}=260)$, compared to

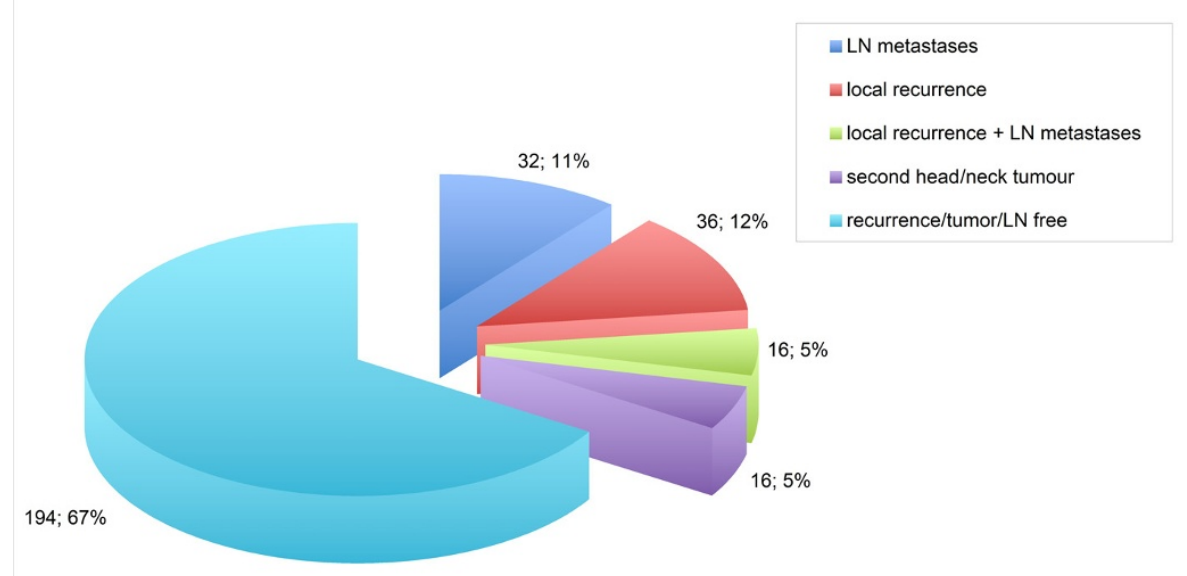

Figure 1 Clinical and radiological assessment of recurrence and lymph node metastases. 


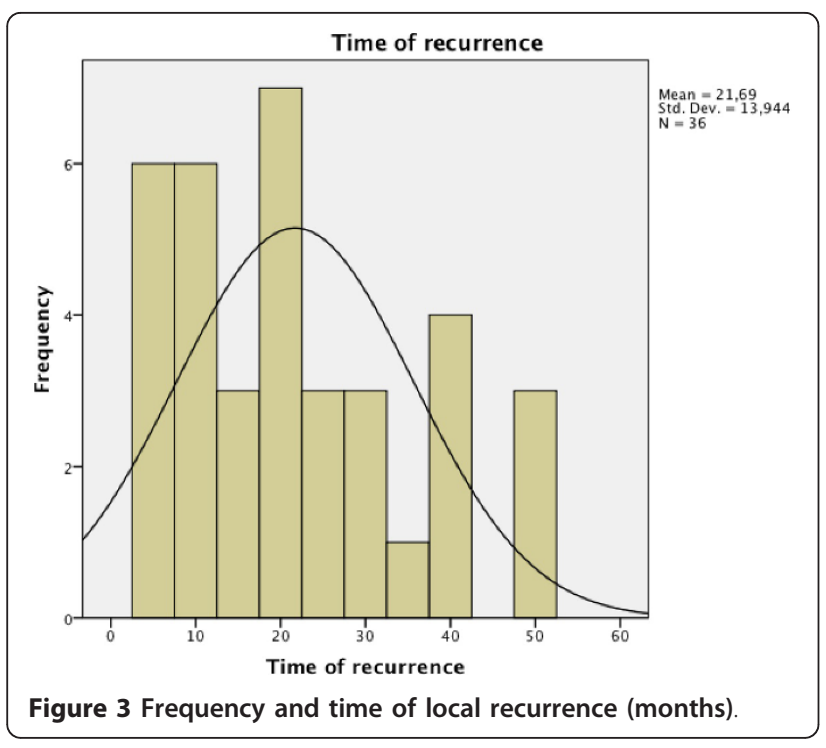

ultrasonography $(\mathrm{DOR}=40), \mathrm{CT}(\mathrm{DOR}=14)$, and MRI $(\mathrm{DOR}=7)$ [9].

Nowadays, FDG-PET seems to play a more and more intensive role in lymph node metastasis or second tumor assessment. Recently Yamazaki et al. studied 1076 lymph nodes with preoperative FDG-PET and CT. FDG-PET detected $100 \%$ of metastatic lymph nodes $\geq$ $10 \mathrm{~mm}$ and intranodal tumor deposits $\geq 9 \mathrm{~mm}$, and had fewer false-positives than did CT [10].

Several CT criteria for assessing nodal metastases have been discussed, like nodal size criteria (greatest diameter more than $1.5 \mathrm{~cm}$ for jugolodigastric and submandibular nodes, more than $1 \mathrm{~cm}$ for all other lymph nodes) nodal shape (more spherical shape in metastastic nodes), nodal grouping (three or more, each with a diameter of

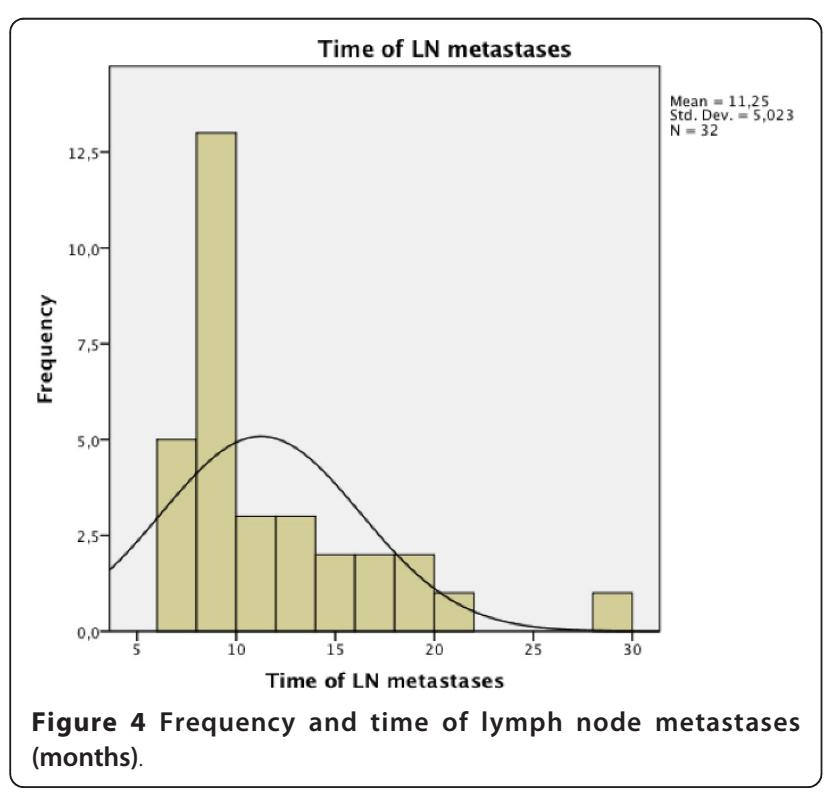

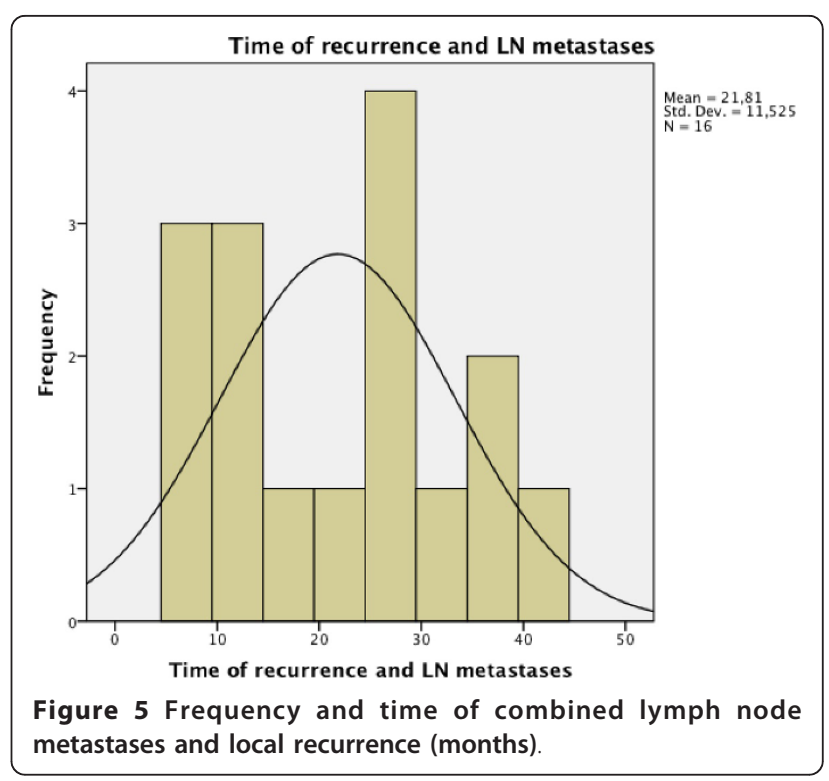

8-15 mm), and central necrosis [11]. But in postoperative or radiated necks, the evaluation appears to be more difficult that in the preoperative status.

Some authors advocate the use of ultrasound due to good results in lymph node control [12] and lower costs, while others $[8,13]$ prefer $\mathrm{CT}$ scans due to a higher sensitivity from $\mathrm{CT}$ imaging in comparison to ultrasound. One reason may be the better detection of deep cervical nodes by CT (Figure 6).

More than two-thirds of locoregional recurrences and lymph node metastases occur within the first two years $[14,15]$. In the present study, local recurrence (Figure 3) appeared later in comparison to lymph node metastases (Figure 4).

Concerning detection of local recurrence by CT scans, data from the literature are not available. In the present study, local recurrence was detected first by CT scans in 4 patients (Figure 2); 3 out of these 4 were localized in the orbit and one in the maxilla (Figure 7). One reason could be that locations like mouth floor or tongue

Table 2 Data of recurrence and LN metastasis (Missing = Patients without local recurrence or LN metastasis during follow-up)

\begin{tabular}{lccc}
\hline & $\begin{array}{c}\text { Time of } \\
\text { recurrence }\end{array}$ & $\begin{array}{c}\text { Time of } \mathbf{L N} \\
\text { metastases }\end{array}$ & $\begin{array}{c}\text { Time of recurrence and } \\
\text { LN metastases }\end{array}$ \\
\hline $\mathrm{N}$ Valid & 36 & 32 & 16 \\
\cline { 2 - 5 } Missing & 48 & 52 & 68 \\
\hline Median & 18,00 & 9,00 & 23,50 \\
\hline $\begin{array}{l}\text { Std. } \\
\text { Deviation }\end{array}$ & 13,944 & 5,023 & 11,525 \\
\hline Minimum & 5 & 7 & 7 \\
\hline Maximum & 51 & 28 & 42 \\
\hline
\end{tabular}




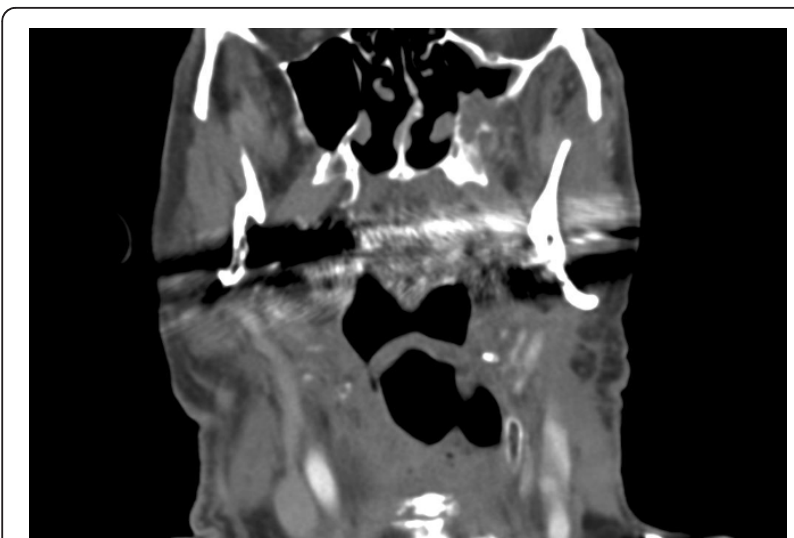

Figure 6 Lymph node metastasis Level II detected by CT-scans.

can be better observed. Therefore, in cases of poorer visual assessment, like in the reconstructed maxilla, CT can be advantageous for local control, whereas ultrasonography does not have a field of indication. Another alternative could be 18F-FDG PET/CT, but it is not available in all hospitals and is more cost intensive. Abgral et al., in 91 patients without clinical evidence of recurrence of head and neck SCC that were examined by $18 \mathrm{~F}-\mathrm{FDG} \mathrm{PET} / \mathrm{CT}$, demonstrated proven recurrence in 30 patients [16].

The present study demonstrates that a reduction in the follow-up period of 5 years is not acceptable, in particular with regard to local recurrences. CT is still indicated for follow-up controls besides the clinical controls, but the alternative of ultrasonography, in particular for neck evaluation, should be taken into further consideration.

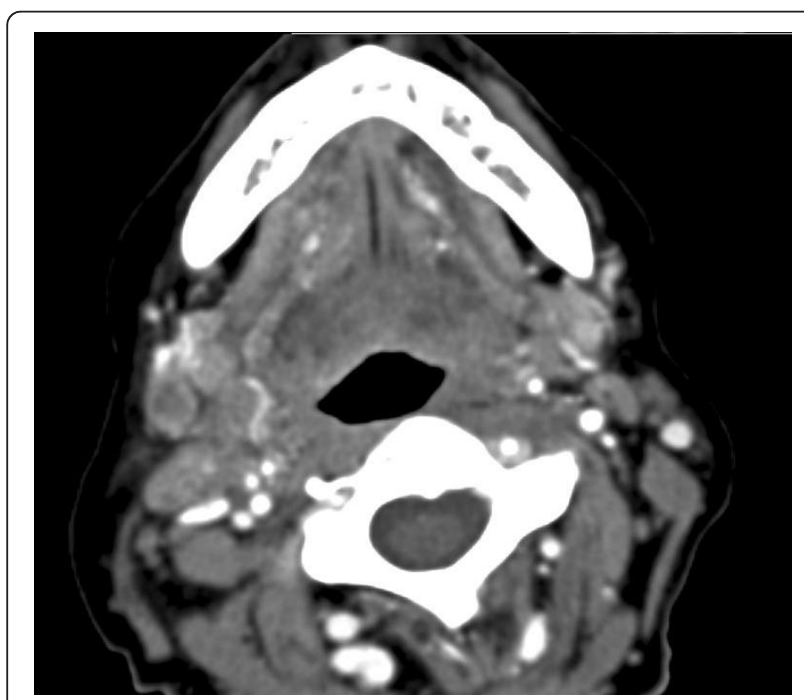

Figure 7 Local recurrence of the maxilla first detected by CTscans.

\section{Conclusion}

Routine CT for follow-up is still indicated for detecting lymph node metastases as well as local recurrence. Ultrasonography does have a growing importance for detection of lymph node metastasis but not for local recurrences. Thorough clinical investigation is of course the baseline diagnostic.

\section{Authors' contributions}

VR and CC carried out the retrospective study, HT and FW drafted the manuscript, MB participated in the design of the study, KW and AK participated in the design and coordination of the study. All authors read and approved the final manuscript.

\section{Competing interests}

The authors declare that they have no competing interests.

Received: 22 December 2010 Accepted: 25 March 2011

Published: 25 March 2011

\section{References}

1. Tytor M, Olofsson J, Ledin T, Brunk U, Klintenberg C: Squamous cell carcinoma of the oral cavity. A review of 176 cases with application of malignancy grading and DNA measurements. Clin Otolaryngol Allied Sci 1990, 15:235-252.

2. Rogers SN, Brown JS, Woolgar JA, Lowe D, Magennis P, Shaw RJ, Sutton D, Errington $D$, Vaughan D: Survival following primary surgery for oral cancer. Oral Oncol 2009, 45:201-211.

3. Boysen M, Natvig K, Winther FO, Tausjo J: Value of routine follow-up in patients treated for squamous cell carcinoma of the head and neck. J Otolaryngol 1985, 14:211-214.

4. Leemans CR, Tiwari R, Nauta JJ, van der Waal I, Snow GB: Recurrence at the primary site in head and neck cancer and the significance of neck lymph node metastases as a prognostic factor. Cancer 1994, 73:187-190.

5. Layland MK, Sessions DG, Lenox J: The influence of lymph node metastasis in the treatment of squamous cell carcinoma of the oral cavity, oropharynx, larynx, and hypopharynx: No versus N+. Laryngoscope 2005, 115:629-639

6. Atula TS, Varpula MJ, Kurki TJ, Klemi PJ, Grenman R: Assessment of cervical lymph node status in head and neck cancer patients: palpation, computed tomography and low field magnetic resonance imaging compared with ultrasound-guided fine-needle aspiration cytology. Eur J Radiol 1997, 25:152-161.

7. Atula TS, Grenman R, Varpula MJ, Kurki TJ, Klemi PJ: Palpation, ultrasound, and ultrasound-guided fine-needle aspiration cytology in the assessment of cervical lymph node status in head and neck cancer patients. Head Neck 1996, 18:545-551.

8. Yousem DM, Som PM, Hackney DB, Schwaibold F, Hendrix RA: Central nodal necrosis and extracapsular neoplastic spread in cervical lymph nodes: MR imaging versus CT. Radiology 1992, 182:753-759.

9. de Bondt RB, Nelemans PJ, Hofman PA, Casselman JW, Kremer B, van Engelshoven JM, Beets-Tan RG: Detection of lymph node metastases in head and neck cancer: a meta-analysis comparing US, USgFNAC, CT and MR imaging. Eur J Radiol 2007, 64:266-272.

10. Yamazaki Y, Saitoh M, Notani K, Tei K, Totsuka Y, Takinami S, Kanegae K, Inubushi M, Tamaki N, Kitagawa Y: Assessment of cervical lymph node metastases using FDG-PET in patients with head and neck cancer. Ann Nucl Med 2008, 22:177-184.

11. Som PM: Detection of metastasis in cervical lymph nodes: CT and MR criteria and differential diagnosis. AJR Am J Roentgenol 1992, 158:961-969.

12. Hohlweg-Majert B, Metzger MC, Voss PJ, Holzle F, Wolff KD, Schulze D: Preoperative cervical lymph node size evaluation in patients with malignant head/neck tumors: comparison between ultrasound and computer tomography. J Cancer Res Clin Oncol 2009, 135:753-759.

13. King AD, Tse GM, Ahuja AT, Yuen EH, Vlantis AC, To EW, van Hasselt AC Necrosis in metastatic neck nodes: diagnostic accuracy of $\mathrm{CT}, \mathrm{MR}$ imaging, and US. Radiology 2004, 230:720-726. 
14. Boysen M, Lovdal O, Tausjo J, Winther F: The value of follow-up in patients treated for squamous cell carcinoma of the head and neck. Eur J Cancer 1992, 28:426-430.

15. Haas I, Hauser U, Ganzer U: The dilemma of follow-up in head and neck cancer patients. Eur Arch Otorhinolaryngol 2001, 258:177-183.

16. Abgral R, Querellou S, Potard G, Le Roux PY, Le Duc-Pennec A, Marianovski R, Pradier O, Bizais Y, Kraeber-Bodere F, Salaun PY: Does 18FFDG PET/CT improve the detection of posttreatment recurrence of head and neck squamous cell carcinoma in patients negative for disease on clinical follow-up? J Nucl Med 2009, 50:24-29.

doi:10.1186/1758-3284-3-18

Cite this article as: Rivelli et al: Screening recurrence and lymph node metastases in head and neck cancer: the role of computer tomography in follow-up. Head \& Neck Oncology 2011 3:18.

Submit your next manuscript to BioMed Central and take full advantage of:

- Convenient online submission

- Thorough peer review

- No space constraints or color figure charges

- Immediate publication on acceptance

- Inclusion in PubMed, CAS, Scopus and Google Scholar

- Research which is freely available for redistribution

Submit your manuscript at www.biomedcentral.com/submit 